Preprint

UCRL-JC-140978

\title{
Progress in Accident
} Analysis of the HYLIFE-II Inertial Fusion Energy Power Plant Design

S. Reyes, J.F. Latkowski, J. Gomez del Rio, and J. Sanz

This article was submitted to

$14^{\text {th }}$ Topical Meeting on the Technology of Fusion Energy, Park City, UT, October $15-19,2000$

U.S. Department of Energy

\section{October 11, 2000}

Lawrence

Livermore

National

Laboratory 


\section{DISCLAIMER}

This document was prepared as an account of work sponsored by an agency of the United States Government. Neither the United States Government nor the University of California nor any of their employees, makes any warranty, express or implied, or assumes any legal liability or responsibility for the accuracy, completeness, or usefulness of any information, apparatus, product, or process disclosed, or represents that its use would not infringe privately owned rights. Reference herein to any specific commercial product, process, or service by trade name, trademark, manufacturer, or otherwise, does not necessarily constitute or imply its endorsement, recommendation, or favoring by the United States Government or the University of California. The views and opinions of authors expressed herein do not necessarily state or reflect those of the United States Government or the University of California, and shall not be used for advertising or product endorsement purposes.

This is a preprint of a paper intended for publication in a journal or proceedings. Since changes may be made before publication, this preprint is made available with the understanding that it will not be cited or reproduced without the permission of the author.

This report has been reproduced

directly from the best available copy.

Available to DOE and DOE contractors from the

Office of Scientific and Technical Information

P.O. Box 62, Oak Ridge, TN 37831

Prices available from (423) 576-8401

http://apollo.osti.gov/bridge/

Available to the public from the

National Technical Information Service

U.S. Department of Commerce

5285 Port Royal Rd.,

Springfield, VA 22161

http://www.ntis.gov/

OR

Lawrence Livermore National Laboratory

Technical Information Department's Digital Library

http://www.llnl.gov/tid/Library.html 


\title{
PROGRESS IN ACCIDENT ANALYSIS OF THE HYLIFE-II INERTIAL FUSION ENERGY POWER PLANT DESIGN
}

\author{
S. Reyes ${ }^{\mathrm{a}, \mathrm{b}}$, J. F. Latkowski ${ }^{\mathrm{a}}$, J. Gomez del Rio ${ }^{\mathrm{b}}$, and J. Sanz ${ }^{\mathrm{b}}$ \\ ${ }^{a}$ Lawrence Livermore National Laboratory, P. O. Box 808, L-632, \\ Livermore, CA 94550, Tel: 925-424-5684

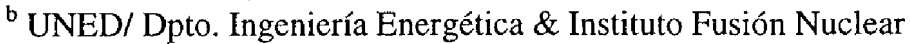 \\ E.T.S. Ingenieros Industriales, C/Ciudad Universitaria s/n, 28040 Madrid (Spain)
}

\begin{abstract}
The present work continues our effort to perform an integrated safety analysis for the HYLIFE-II inertial fusion energy (IFE) power plant design. Recently we developed a base case for a severe accident scenario in order to calculate accident doses for HYLIFE-II. It consisted of a total loss of coolant accident (LOCA) in which all the liquid flibe $\left(\mathrm{Li}_{2} \mathrm{BeF}_{4}\right)$ was lost at the beginning of the accident. Results showed that the off-site dose was below the limit given by the DOE Fusion Safety Standards for public protection in case of accident, and that this dose was dominated by the tritium released during the accident.
\end{abstract}

In order to further advance a complete safety analysis for HYLIFE-II, a range of other accident scenarios must be considered. In this work, we introduce a new version of the MELCOR thermal-hydraulics code recently developed by the Idaho National Engineering and Environmental Laboratory (INEEL) that uses flibe as the working fluid. We have focused on a loss of flow accident (LOFA), with simultaneous failure of the blanket structure. Additionally, partial/total breakage of the beam tubes that connect the chamber with the outside of the confinement building is assumed. The postulated failure of the beam tubes constitutes the bypass needed to communicate the target chamber with the environment. Once the release fractions of the various radioactivity sources are known, we calculate off-site doses under different conditions as a consequence of the accident.

\section{INTRODUCTION}

The HYLIFE-II power plant concept ${ }^{1}$ is based on non-flammable, renewable liquid wall target chambers formed with flibe molten salt jets, a heavy-ion driver, and double-sided illumination of indirect drive targets. The liquid wall serves to attenuate fast neutrons before they strike the first structural wall (FSW), lengthening the lifetime of components and also serves to breed tritium fuel. Flibe shielding circuits inside the target chamber include oscillating flow and steady flow. Two more flibe circuits are contained in the blanket assembly procuring cooling and shielding to these structures.

Recently, we modeled a severe accident analysis for HYLIFE-II in order to calculate accident doses. ${ }^{2}$ It consisted of a total loss of coolant accident (LOCA) with simultaneous breakage of $100 \%$ of the beam tubes and failure of both the inner shielding and confinement buildings. The only flibe mass that was available for mobilization in this case was the fraction vaporized by the $\mathrm{x}$-rays from the last ignited target, given that all the liquid flibe was assumed to be lost. This vapor was then treated as an aerosol in the thermal-hydraulics calculations in order to obtain the accidental release fraction. Results showed that the off-site dose to the most exposed individual (MEI) was below the $1 \mathrm{rem}$ limit given by the DOE Fusion Safety Standards ${ }^{3}$ for public protection in case of accident. The fraction of tritium released during the accident was the most important contributor to this result.

Here, we consider a range of other accident scenarios, using a new version of the MELCOR thermalhydraulics code $^{4}$ recently developed by INEEL, which introduces flibe as the working fluid. During a loss of flow accident, which could be initiated by failure of the pumping system, the flibe present inside the target chamber (the fraction vaporized during the last shot plus the flibe from the protective liquid wall) will be available for mobilization and release. Further, we estimate the flibe release fraction in the case that there was a failure in the blanket structure. In this case the entire flibe inventory present in the first wall/blanket assembly in the moment of the accident would also be available for mobilization. In order to obtain a radioactivity fraction released to the environment, we postulate a break in the beam tubes outside of the reactor building. This constitutes the bypass needed to communicate the target chamber with the environment. With the results on the radioactivity release 
fractions, and the adequate dose conversion factors (DCF), the accident dose may be calculated.

\section{COMPUTER CODES AND METHODOLOGY}

In order to perform accident doses analysis, first one needs to know the fraction of the radioactivity source term that is released to the environment. Neutron transport and activation, heat transfer, and thermalhydraulics and aerosol transport calculations have been performed.

TART $^{5}$ Monte Carlo transport code has been used for neutron transport calculations. Activation of components and decay heat results were obtained from the $\mathrm{ACAB}^{6}$ activation code following 30 years of plant operation.

The CHEMCON $^{7}$ heat transfer code is used to simulate the time-temperature histories of the structures during the transient, resulting from the decay heat of activated structures. The temperature excursion of the different components is then used to determine the activation products source term available for mobilization, which will later be used for the MELCOR calculations.

The MELCOR thermal-hydraulics code is capable of simulating a wide range of physical phenomena, which include heat transfer, aerosol physics and fusion product release and transport. The original version of the code, traditionally used by the fission community, has been adapted for fusion accident analysis by INEEL. This work uses a new version of the code that substitutes flibe for water as the working fluid. With these data about the radioactivity released, and the adequate DCF, off-site doses under different accident conditions can be obtained. Data on DCF have been calculated using MACCS2 accident consequences code. ${ }^{8}$

\section{TIME-TEMPERATURE HISTORY OF THE REACTOR COMPONENTS}

During a thermal transient in the plant, the potential energy sources must be identified in order to determine the temperature excursions of the different components. In this case the only energy source is the radioactive decay heat from the activated material in the reactor structures. Once the accident begins it is conceivable that fusion reactions could continue to occur for a short period of time. Several factors must be considered: accelerator operation, target injection, and beam propagation through a varying environment. If accelerator operation and target injection both continue, then beam propagation will determine when ignition is no longer possible. We have assumed that the beam tubes failure occurs outside the confinement building, allowing the air to penetrate the chamber, and resulting in the inability to propagate the heavy ion beams to the target.

Considering then that the decay heat from activated materials is the only energy source during the transient, a CHEMCON calculation was developed using a simple HYLIFE-II 1-D cylindrical model. This model consists of four stainless steel shells that represent the FSW/blanket structure. It also includes the flibe trapped in these structures during the LOFA, an inner concrete shield and the confinement building. Fig. 1 shows the timetemperature history of the different components during the transient.

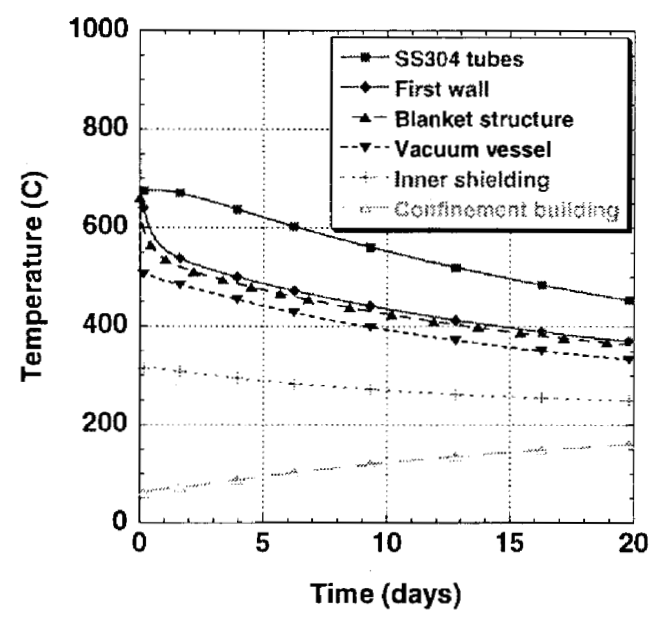

Figure 1. Time-temperature history of the various reactor components due to the radioactive decay heat.

Due to the low radioactive afterheat, the first wall temperature, initially at $675{ }^{\circ} \mathrm{C}$, experiences an insignificant peak of tenths of a degree at about 10 hours, after which it gradually falls. This indicates that the stainless steel temperature will remain far below its melting point during the all transient $\left(\mathrm{T}_{\text {melt }} \approx 1400{ }^{\circ} \mathrm{C}\right)$. This result eliminates the possibility of volatilization of activated stainless steel or any over-stress damage during the accident.

\section{ACTIVATION PRODUCTS SOURCE TERM}

There are three main radioactivity sources to be considered in HYLIFE-II. First is the flibe with its activation products. When we studied the total LOCA the only flibe mass to be considered were the $10 \mathrm{~kg}$ vaporized by the $\mathrm{x}$-rays from the last ignited target. However, in this case and as a consequence of the loss of flow, the protective liquid wall in front of the FSW would also be standing as a pool inside the target chamber. If additionally we assume a break in the blanket piping, then 
the flibe from the blanket cooling and shielding circuits would leak inside the chamber. That would result in a total mass of about 140 tonnes of flibe available for mobilization in this case.

Second, we assume that the corrosion of type 304 stainless steel (SS304) by flibe within the chamber and blanket can be limited to $1 \mu \mathrm{m} / \mathrm{y}$ via corrosion control methods. Additionally, we assume that the flibe clean-up system can maintain the mobilizable inventory of corrosion products to a 1-y supply. Given a total surface area of $1040 \mathrm{~m}^{2}$, we obtain a corrosion product inventory of $8.3 \mathrm{~kg}$ in the total flibe volume. Also, using data from oxidation-driven mobilization experiments on PCA performed at INEEL, we calculate an additional $0.5 \mathrm{~kg}$ of stainless steel that would be oxidized at the accident temperatures (we assume that SS304 mobilization will be the same as that from PCA). ${ }^{9,10}$ Adding up the corrosion and oxidation products, we obtain $\approx 10 \mathrm{~kg}$ of SS304 in the total flibe volume. Considering that only $5 \%$ of the flibe inventory is present in the chamber at any given time, we obtain a total of $0.5 \mathrm{~kg}$ of SS304 mobilized during the transient.

Finally, it is estimated that approximately $140 \mathrm{~g}$ of tritium would be trapped within the chamber, blanket and piping. We conservatively assume that the entire tritium inventory is converted to the more radiotoxic HTO form, yielding a total mass of $1 \mathrm{~kg}$ of HTO.

\section{RADIOACTIVITY RELEASE AND OFF-SITE DOSES}

In order to estimate release fractions, a MELCOR model of HYLIFE-II was developed. This model consists of the FSW and blanket structures, beam tubes (considering an updated HYLIFE-II version which includes 96 beams per side), inner shield and confinement building. The heavy-ion beam tubes and the target chamber are assumed to be at vacuum. The radioactive source term described in the previous section is supposed to be available for mobilization during the transient. This version of the MELCOR code uses flibe as the operating fluid. MELCOR heat transfer package considers conduction, convection and radiation between the structures. The aerosol transport module treats the aerosol nucleation and agglomeration, vapor condensation, gravity settling and gaseous/liquid transport.

\section{A. Flibe Release and Off-site Doses}

We have performed a series of MELCOR calculations in order to characterize the behavior of the flibe in accidental conditions not involving the total loss of the liquid coolant previously addressed. We assume a LOFA accident with failure in the blanket structure and a break in the beam tubes that would constitute a bypass between the target chamber and the environment. We have assumed different severities of the tubes breakage, ranging from the total failure of the 192 beam tubes to the case were a single tube breaks. The occurrence of blanket flibe leakage directly to the beam tubes was also studied. Given that a special region of concrete shielding for the focusing magnets isolates the beam tubes from the blanket, we discarded this possibility. We have obtained the released mass in each scenario and then considered three sets of accident conditions for off-site dose calculations purposes. First set is called Typical Case with Ground Release (TCGR) and assumes average weather conditions (wind speed $=4 \mathrm{~m} / \mathrm{s}$, atmospheric stability class D), and radioactivity release at ground level. Second, the Typical Case with Elevated Release (TCER), also considers average weather conditions but the release is produced trough a smokestack $100 \mathrm{~m}$ above ground level (TCHR). Finally the Bounding Case with Ground Release (BCGR) considers conservative weather conditions (wind speed $=1 \mathrm{~m} / \mathrm{s}$, atmospheric stability class F) and ground level release. Table 1 shows the results for mass released and off-site doses in the different described scenarios.

Table 1. Released flibe mass $(\mathrm{kg})$ and off-site doses (mrem)

\begin{tabular}{|c|c|c|c|c|}
\hline $\begin{array}{c}\text { Beam tubes } \\
\text { failure fraction }\end{array}$ & $\begin{array}{c}\text { Mass } \\
\text { released }\end{array}$ & $\begin{array}{c}\text { Dose } \\
\text { TCGR }\end{array}$ & $\begin{array}{c}\text { Dose } \\
\text { TCER }\end{array}$ & $\begin{array}{c}\text { Dose } \\
\text { BCGR }\end{array}$ \\
\hline $100 \%$ & 5.54 & 1.24 & 0.23 & 16.6 \\
\hline $50 \%$ & 4.56 & 1.02 & 0.19 & 13.7 \\
\hline $25 \%$ & 2.63 & 0.59 & 0.11 & 7.89 \\
\hline 1 beam tube & 0.13 & 0.03 & 0.005 & 0.39 \\
\hline
\end{tabular}

Given the low afterheat and the temperature decrease of structures during the transient, the liquid flibe is not going to suffer volatilization and will mostly remain in the form a pool in the chamber/blanket area. The $10 \mathrm{~kg}$ of vaporized flibe generated by the last target, will immediately be converted into fog at the beginning of the accident, and then transported from the chamber to the beam tubes, allowing some of this fog to deposit on structures before reaching the environment. In the first three cases $(100 \%, 50 \%$ and $25 \%$ of beam tubes failing), the mass released turns out to be larger that that obtained in the LOCA study, where we only accounted for the 10 $\mathrm{kg}$ of vapor and obtained a release fraction of $11 \%$. This is because then, we considered that the beam tubes would fail inside the inner shield building, having then to travel from here to the confinement building and next to the environment through the postulated breaks in the walls. This scenario allowed larger surface areas so as a longer 
travel time for the flibe to deposit before leaking through the breach in the confinement building wall.

Results show that even in the case of $100 \%$ beam tubes failure, the dose in the most pessimistic conditions is less than $20 \mathrm{mrem}$, demonstrating the inherent radiological safety of the HYLIFE-II design relative to the use of flibe. It must be noticed that the isotope ${ }^{18} \mathrm{~F}$ contributes in a $99 \%$ to the final dose.

Other than activation concerns, flibe has some chemical and toxicity issues. First and foremost, the escaping beryllium compounds, notably $\mathrm{BeF}_{2}$, pose a health hazard. The recommended limit is $25 \mu \mathrm{g} / \mathrm{m}^{3}$ for peak exposure to beryllium and its compounds. ${ }^{11}$ If we assume a release of $1 \mathrm{~kg}$ of flibe (containing $340 \mathrm{~g}$ of $\mathrm{BeF}_{2}$ ) that escaped to the environment under conservative weather conditions over a period of 1 hour, the concentration at a $1 \mathrm{~km}$ site boundary would only temporarily reach $3 \mu \mathrm{g} / \mathrm{m}^{3}{ }^{12}$ However, the beryllium concentration within the plant could require worker protection. Another concern relative to the use of flibe in HYLIFE-II is the potential of HF formation. When the lithium is fissioned by neutron interaction, it leaves a free fluorine atom, which could combine with available hydrogen. HF poses a corrosion threat and has its own health risks. One method that has been proposed to control flibe $\mathrm{pH}$ is the presence of beryllium flowing pebbles or fingers which would allow the $\mathrm{HF}$ or free fluoride ions to react back to $\mathrm{BeF}_{2} \cdot{ }^{13}$

\section{B. SS304 Release and Off-site Doses}

With the previously described MELCOR model we also obtained the release fractions of SS304 corrosion and oxidation products in the various scenarios. An initial mass of $0.5 \mathrm{~kg}$ was used for the aerosol source term and the aerosol nucleation and agglomeration, gravity settling and transport during the accident were simulated. We also calculated the correspondent DCF for the different accident conditions and results are shown in table 2.

Table 2. Released SS304 mass ( $\mathrm{kg}$ ) and off-site doses (mrem)

\begin{tabular}{|c|c|c|c|c|}
\hline $\begin{array}{c}\text { Beam tubes } \\
\text { failure fraction }\end{array}$ & $\begin{array}{c}\text { Mass } \\
\text { released }\end{array}$ & $\begin{array}{c}\text { Dose } \\
\text { TCGR }\end{array}$ & $\begin{array}{c}\text { Dose } \\
\text { TCER }\end{array}$ & $\begin{array}{c}\text { Dose } \\
\text { BCGR }\end{array}$ \\
\hline $100 \%$ & 0.27 & 1.40 & 0.13 & 20.9 \\
\hline $50 \%$ & 0.22 & 1.13 & 0.11 & 16.8 \\
\hline $25 \%$ & 0.12 & 0.64 & 0.06 & 9.60 \\
\hline 1 beam tube & 0.009 & 0.05 & 0.004 & 0.68 \\
\hline
\end{tabular}

It can be observed that in the most pessimistic case $(100 \%$ of the beam tubes fail and conservative weather conditions with ground release) the accident dose to the public would be less than 21 mrem. In this case about $75 \%$ of the total dose comes from the radioisotope ${ }^{60} \mathrm{Co}$, being followed in importance by the isotopes ${ }^{58} \mathrm{Co}$ and ${ }^{59} \mathrm{Fe}$. It must be pointed out that in the first three beam tubes failure cases, the radioactivity release results to be larger than that obtained in the LOCA analysis (only 0.07 $\mathrm{kg}$ of SS304 were released then). This is due to the effect of the smaller available surface for aerosol deposition and shorter travel time to the environment in this particular bypass scenario.

\section{HTO Release and Off-site Doses}

In order to simulate the HTO transport and condensation on structures we made use of a former version of the MELCOR code which uses water as the working fluid in stead of flibe (at this point no-multifluid version of the code is available yet). An instantaneous release of the tritium from the SS304 structures was assumed. Calculations of tritium migration from the stainless steel shells were also developed using TMAP (Tritium Migration Analysis Program). These calculations showed that at the operating temperature of $675^{\circ} \mathrm{C}$, the tritium migration from the steel is fast enough $(>90 \%$ in only 1.5 hour) that there is no difference when comparing with the results from the instantaneous migration assumption. ${ }^{14}$ Results show that in this case $100 \%$ of the tritium is released. The non-existence of a cold structure (like the confinement building wall in the case of the LOCA analysis) where this tritium would condense and avoid being released, leads to the result of a $1 \mathrm{~kg}$ of HTO release to the environment.

The consequent off-site dose from the tritium in case of average weather conditions with ground level release would be $0.5 \mathrm{rem}$. The dose would result in only $47 \mathrm{mrem}$ if the release occurred through an elevated stack. If pessimistic weather conditions were assumed instead, then the accident dose would be $6.4 \mathrm{rem}$. As occurred in the case of the LOCA accident, the tritium dominates the total result, being the contributions of the flibe and SS304 less than $10 \%$ of the final accident dose.

\section{CONCLUSIONS}

Recently, we developed an accident analysis for HYLIFE-II consisting on a total LOCA. As a consequence of the loss of coolant, no flibe was involved in the accident except for the fraction vaporized by the $\mathrm{x}$ rays from the last reactor shot.

In this work we use a new version of the MELCOR thermal-hydraulics code that substitutes flibe for water as the working fluid. We have developed an analysis for a 
LOFA accident, including failure of the blanket structure and partial/total breakage of the beam tubes that communicate the chamber to the environment.

Results show that the radioactive afterheat from activated components is low enough to allow cooling of structures during the transient. Even though the entire flibe inventory present in the chamber and blanket at the moment of the accident is available for mobilization, the release fraction is small enough to result in off-site doses lower than $20 \mathrm{mrem}$, demonstrating the inherent radiological safety of HYLIFE-II relative to the use of flibe. This flibe together with the stainless steel corrosion and oxidation products contribute to the final off-site dose with less than the $10 \%$ of the total. The final accident dose is clearly dominated by the $140 \mathrm{~g}$ of tritium trapped in the stainless steel structures and released during the accident.

For the most pessimistic scenario, where a failure of all of the beam tubes occurs, we obtain an accident dose of $0.5 \mathrm{rem}$. This dose considers average weather conditions (as recommended by DOE Fusion Safety Standards) and assumes ground level release. This result is below the $1 \mathrm{rem}$ limit for public protection in case of accident, and means that an evacuation plan would not be needed in this case.

In order to maximize the potential of IFE as a safe and environmentally attractive energy source, more effort is needed in this area. Future work will include identification of accident initiators and sequences in order to analyze other accident scenarios, so as work in alternative IFE concepts such as dry-wall, laser-driven designs.

\section{ACKNOWLEDGEMENTS}

The authors would like to thank their colleagues at the INEEL for their assistance and recommendations that have been essential to the completion of the above work.

Work performed under the auspices of the U. S. Dept. of Energy by University of California Lawrence Livermore National Laboratory under Contract W-7405Eng-48 and under support Ministerio de Educación y Cultura, Spain, under Plan Nacional I+D+I (2000-2003) Programa Nacional de Fusion Termonuclear, and the European Union keep-in-touch Program on IFE.

\section{REFERENCES}

[1] R. W. Moir, et al., "HYLIFE-II: A Molten Salt Inertial Fusion Energy Power Plant Design - Final Report," Fus. Technol. 25, 5-25 (1994).
[2] S. Reyes, J. F. Latkowski, J. Gomez del Rio and J. Sanz, "Accident Consequences Analysis of the HYLIFE-II Inertial Fusion Energy Power Plant Design," Presented at the $13^{\text {th }}$ International Symposium on Heavy Ion Inertial Fusion, March 1317, 2000, San Diego, California (2000).

[3] "Safety of Magnetic Fusion Facilities: Guidance," DOE-STD-6003-96, U. S. Department of Energy, Washington, D. C. (1996).

[4] R. O. Gauntt, R. K. Cole, S. A. Hodge, S. B. Rodriguez, R. L. Sanders, R. C. Smith, D. S. Stuart, R. M. Summers and M. F. Young, "MELCOR Computer Code Manuals," NUREG/CR-6119, Vol. 1, Rev. 1, SAND97-2398 (1997).

[5] D. E. Cullen, "TART98: A Coupled Neutron Photon, 3-D, Combinatorial Geometry, Time Dependent, Monte Carlo Transport Code," LLNL, UCRL-ID126455, Rev. 2 (1998).

[6] J. Sanz, "ACAB98: Activation code for fusion applications. User's Manual V4.0," Universidad Nacional de Educacion a Distancia (UNED), LLNL, UCRL-CR-133040 (1999).

[7] M. J. Gaeta and B. J. Merrill, "CHEMCON User's Manual Version 3.1," Idaho National Engineering and Environmental Laboratory, INEL-95/0147 (1995).

[8] D. Chanin and M. L. Young, "Code Manual for MACCS2, User's Guide," NUREG/CR-6613, Vol. 1, SAND97-0594 (1998).

[9] K. A. McCarthy, G. R. Smolik, D. L. Hagrman, and D. A. Petti, "Summary of Oxidation Driven Mobilization Data and Their Use in Fusion Safety Assessments," J. Nucl. Mater. 233-237 (1996) 16071611.

[10] G. R. Smolik, W. J. Carmack, and K. Coates, "Mobilization from Austenitic Stainless Steel During Air and Steam Exposures," Idaho National Engineering and Environmental Laboratory, ITER/US/97/TE/SA-25 (1997).

[11] "NIOSH Pocket Guide to Chemical Hazards", National Institute for Occupational Safety and Health, Department of Health and Human Services publication 97-140 (1997).

[12] T. J. Dolan and G. R. Longhurst, "Safety and Environmental Aspects of HYLIFE-II," Fus. Technol. 19, 1392-251397 (1991).

[13] L. C. Cadwallader and G. R. Longhurst, "Flibe Use in Fusion Reactors: An Initial Safety Assessment," Idaho National Engineering and Environmental Laboratory, INEEL/EXT-99-00331 (1999).

[14]Rion Causey and Thomas Venhaus, personal communication (2000). 


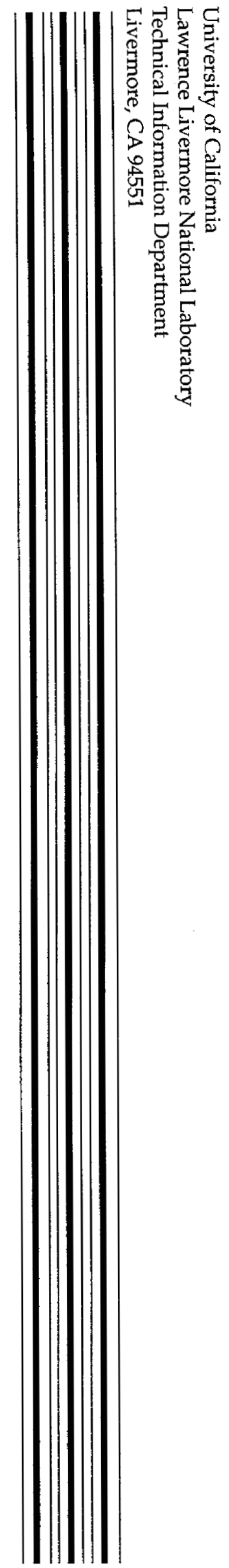

